\title{
TANDEM: NOVAS FORMAS DE APRENDER E ENSINAR LIBRAS E PORTUGUÊS
}

Tandem: nuevas formas de aprender y enseñar libra y portugués

Tandem: new ways to learn and teach libras and portuguese

\section{Ronny Diogenes Menezes ${ }^{1}$}

\section{RESUMO}

Com o objetivo de contribuir para a aquisição da Libras e do Português por Surdos, este projeto implantou o Tandem como mediador da aprendizagem para alunos dos cursos de Licenciatura do Ceres/UFRN e comunidade surda de Caicó-RN. O Português tem se tornado um objeto de difícil compreensão por muitos surdos, no mesmo caminho, encontra-se a aprendizagem da Libras por pessoas ouvintes, muitos não encontram o necessário para se aprofundar na língua por meio das disciplinas dos cursos superiores. Para resolver esse problema, utilizamos o Tandem como uma ferramenta social para a aprendizagem de Libras e Português. Com isso, utilizamos interações presenciais na modalidade Tandem como meio para que surdos e ouvintes possam, colaborativamente, caminhar na aquisição dessas línguas.

Palavras-chave: Surdos, metodologias ativas, inclusão.

\footnotetext{
${ }^{1}$ Mestre em Formação de Professores. Docente do Departamento de Educação, Ceres - UFRN
} 


\section{RESUMEN}

Con el objetivo de contribuir a la adquisición de Libras y Português por los Sordos, este proyecto implementó Tandem como un mediador de aprendizaje para los estudiantes de los cursos de Licenciatura en Ceres / UFRN y la comunidad de sordos en Caicó-RN. El portugués se ha convertido en un objeto de difícil comprensión para muchas personas sordas, en el mismo camino está el aprendizaje de Libras por personas oyentes, muchos no encuentran lo necesario para profundizar en el idioma a través de las disciplinas de los cursos de educación superior. Para resolver este problema utilizamos Tandem como una herramienta social para aprender Libra y Portugués. Así, utilizamos las interacciones cara a cara en la modalidad Tandem como un medio para que las personas sordas y oyentes puedan, de forma colaborativa, caminar en la adquisición de estos idiomas.

Palabras clave: Personas sordas, metodologías activas, inclusión.

\section{ABSTRACT}

With the objective of contributing to the acquisition of Libras and Português by the Deaf, this project implemented Tandem as a mediator of learning for students in the Licentiate Degree courses at Ceres/UFRN and the deaf community in Caicó-RN. Portuguese has become an object of difficult understanding for many deaf people, in the same path is the learning of Libras by hearing people, many do not find what is necessary to deepen in the language through the disciplines of higher education courses. To solve this problem we use Tandem as a social tool for learning Libras and Portuguese. Thus, we use face-to-face interactions in the Tandem modality as a means so that deaf and hearing people can, collaboratively, walk in the acquisition of these languages.

Keywords: Deaf people, active methodologies, inclusion. 


\section{EM QUE CONSISTE A PRÁTICA A SER RELATADA}

A linguagem proporciona ao ser humano a oportunidade de crescer e desenvolver suas habilidades de convívio social, e é na interação com o outro que acontecem as descobertas. Desse modo, um uso adequado da língua proporciona aos alunos meios para o desenvolvimento de suas relações humanas, sejam elas pessoais ou profissionais (CANDIDO, 2011; SILVA 2016). A partir disso, o professor de Línguas assume um papel fulcral no estímulo às competências comunicativas dos seus educandos. Entretanto, a atuação do professor de uma língua adicional, em cursos de licenciatura, fica limitada pois os estudantes podem não ter muitas oportunidades de interação com falantes nativos do idioma alvo do ensino. Além disso, muitas instituições têm incluído a Libras de forma burocrática (SKLIAR, 2017), apenas para obedecer à lei e, nesses casos, os estudantes não têm a oportunidade de aprofundar seus conhecimentos sobre essa língua e a cultura Surda.

Assim, os estudantes de licenciaturas que estão cursando a disciplina Libras necessitam de meios para usar a língua em situações reais de comunicação. Em minha experiência como docente, foi possível perceber que uma parte dos alunos não consegue oportunidades para interagir com pessoas surdas, e isso limita a sua aprendizagem e aquisição da língua. A necessidade de que esses futuros professores se tornem fluentes é percebida ao analisar as atuais políticas públicas para a educação de surdos. O Plano Nacional de Educação (PNE) garante aos surdos a matrícula em escolas bilíngues, e a simples conclusão da disciplina Libras não dá ao professor subsídios para ministrar aulas nessa língua nem tão pouco se comunicar de maneira efetiva com alunos surdos.

Não são somente os ouvintes que enfrentam problemas com a língua. Há uma crença de que basta escrever uma palavra em um papel e o surdo irá entender, mas isso não acontece como alguns pensam (STREIECHEN, 2011). A pessoa surda necessita de referenciais visuais para assimilar um conceito, um exemplo disso é apresentado por Streiechen (2011). Uma criança ouvinte, ao utilizar a palavra "cavalo", poderá usar todo um repertório linguístico para entender as variantes dela, como as palavras: Cavalgar, cavaleiro, cavalete, cavalinho e outras, e ao chegar na escola, "seu vocabulário é amplo e suficiente para produzir textos" (STREIECHEN, 2011, p.161). Porém, os surdos necessitam de alguns recursos diferenciados para dominar a compreensão desses conceitos, cada palavra precisa ser apresentada e associada a uma imagem correspondente a ela. Não adianta apenas mostrar o sinal, ou somente a palavra, o professor precisa situar cada variação dela dentro de um contexto.

Vários pesquisadores defendem que um ambiente bilíngue é o que mais contribui para que o estudante surdo possa adquirir a Libras como primeira língua e o Português como língua adicional 
(QUADROS, 2006; FERNANDES, 2016; SKLIAR, 2017). Entretanto, o nosso país ainda está longe de conseguir oferecer a educação bilíngue para todas as crianças surdas, mesmo com a inclusão da meta 4.7, do PNE, que pretende "garantir a oferta de educação bilíngue, em Língua Brasileira de Sinais - LIBRAS como primeira língua e na modalidade escrita da Língua Portuguesa como segunda língua, aos/às alunos/as surdos e com deficiência auditiva de 0 (zero) a 17 (dezessete) anos".

Além do elencado acima, encontramos nos cursos de licenciatura apenas uma disciplina para que o futuro professor possa conhecer e utilizar a Libras. Nesse contexto, os surdos são privados de uma educação de qualidade, pois o processo de formação docente não dá subsídios para que o futuro professor adquira fluência. Assim, nosso projeto proporcionou meios para que os alunos da disciplina Libras das Licenciaturas do Centro de ensino superior do Seridó da Universidade Federal do Rio Grande do Norte (Ceres-UFRN) possam aprender a Libras e pessoas surdas possam aprender a modalidade escrita da língua portuguesa através de interações presenciais na modalidade Tandem.

Por conseguinte, é preciso compreender o que é Tandem. Essa palavra é derivada da língua inglesa e descreve bicicletas que duas pessoas podem pedalar, colaborando para que ambos cheguem ao mesmo destino. Da mesma forma, a aprendizagem através do Tandem "consiste no intercâmbio e compartilhamento de conhecimento entre indivíduos de culturas diferentes, com propósitos de aprendizagem de línguas de modo colaborativo" (BENEDETTI, 2010, p. 21).

Com isso, no nosso caso, um surdo e um ouvinte foram parceiros e trilharam juntos o caminho para o ensino e aprendizagem de duas línguas. Esse processo é baseado na teoria sociointeracionista de Vygotsky (1979) que tem por base a aproximação e o engajamento em atividades sociais e, além disso, a interligação de conceitos cotidianos aos científicos, utilizando artefatos culturais adequados para mediar esse processo de ensino e aprendizagem.

A partir do momento em que um artefato é utilizado para um propósito específico ele transforma-se em uma ferramenta (VIEIRA-ABRAHÃO, 2012, p. 7). Dessa forma, a interação através do Tandem também se encaixa nessa classificação, pois ela tem o potencial de transmitir a cultura de dois grupos de pessoas, além de toda uma carga social e simbólica proveniente das experiências de vida dos interagentes. Essa carga pode ser utilizada para que haja uma aproximação da cultura do outro, pois segundo Vygotsky (1979) a linguagem, e consequentemente o contato com a língua do outro, é muito importante na formação do sujeito.

Por fim o Tandem Libras/Português é uma ferramenta social que proporciona aos aprendizes de duas línguas a oportunidade de mergulhar na cultura de um povo. Esse mergulho é fundamental para que o processo de aquisição/aprendizagem seja desenvolvido, pois “o conhecimento é constru- 
ído socialmente e emerge das práticas sociais” (VIEIRA-ABRAHÃO, 2012, p. 459).

Esse projeto de ensino contribuiu para que os nossos alunos pudessem aprimorar seus conhecimentos da Libras, e assim estabelecer interações e trocas basilares entre professores e alunos e comunidade externa. Desta forma, os licenciandos que participaram deste projeto puderam vivenciar a cultura surda através de interações em contextos autênticos e com falantes nativos da Libras e isso lhes deu condições de se comunicar com seus futuros alunos surdos de maneira mais efetiva, contribuindo para a inclusão dessas pessoas e uma melhor preparação para sua futura inclusão no mercado de trabalho.

\section{CONTEXTO EM QUE OCORRE A AÇÃO}

O Centro de Ensino Superior do Seridó da Universidade Federal do Rio Grande do Norte está inserido em um contexto social que faz com que sua presença seja fundamental para o desenvolvimento local. Em sua fundação, há mais de 40 anos, ele vem contribuindo para o crescimento da região que está inserido. Esse campus da UFRN oferece cursos de Licenciatura em Pedagogia, Matemática, História e Geografia. Além disso, oferece vagas nos bacharelados em Sistema de Informação, Ciências Contábeis e Direito. Entretanto, o projeto foi aplicado somente aos alunos das licenciaturas devido a carência de profissionais da educação habilitados para a educação de surdos.

Na cidade de Caicó, a educação de surdos carece de atenção, pois não existem políticas locais que favoreçam esse processo. $\mathrm{O}$ abandono escolar é frequente na comunidade surda local e outros são constantemente reprovados. Isso faz que muitos surdos sejam adultos, mas ainda não tenham concluído o ensino médio. Em resultado disso, vários surdos não conseguiram resultados satisfatórios no ENEM tendo que adiar o seu sonho de ingressar em um curso superior. Entretanto, dois surdos que participaram do projeto conseguiram aprovação através do Enem nos cursos de licenciatura em física e bacharelado em moda do IFRN de Caicó. Atualmente, na cidade de Caicó, está em funcionamento a Associação Caicoense de Surdos - ACAS e cerca de 40 surdos participam efetivamente das atividades dessa associação, e a aprovação dos dois surdos motivou os seus colegas a também buscar o projeto para se desenvolver. Outro fator que tornou necessária a execução do projeto é a necessidade formar profissionais que possam atender as necessidades comunicacionais dos surdos.

Mesmo com essa instituição se preocupando com a inclusão e os direitos das pessoas com surdez, esse público vem enfrentando dificuldades. Uma delas é a falta de domínio da língua portuguesa e falta de profissionais habilitados para atender os surdos. Vários dos usuários da ACAS 
já tiveram que recorrer ao ministério público para ter o direito à acessibilidade comunicacional. A maioria dessas demandas foi ligada à falta de profissionais habilitados para a tradução e interpretação da Libras e da falta de professores preparados para atender aos alunos da rede pública. Nesse ínterim, surge a motivação para execução do projeto "Tandem Libras/ português: aprendizagem colaborativa de línguas". Pois com ele seria possível contribuir para a inclusão das pessoas surdas dando uma base sólida de comunicação para os futuros professores. Essas sementes plantadas poderiam dar frutos e no futuro promover a acessibilidade para surdos.

\section{PARTICIPANTES/INTEGRANTES DA AÇÃO RELATADA}

Três grupos foram fundamentais na condução desse projeto, primeiramente a comunidade surda local que foi representada contactada através da ACAS, em contato com membros dessa associação foi emitido um convite para participação no projeto e prontamente foi aceito, assim 20 surdos participaram das atividades do Tandem. Apenas um deles tem um curso superior completo e a maioria têm apenas o ensino fundamental completo. Porém são usuários fluentes da Libras o que possibilitou a sua participação plena nas interações no Tandem.

Além desses, participaram também desse projeto alunos das diversas licenciaturas do Ceres-UFRN. A disciplina “LÍNGUA BRASILEIRA DE SINAIS - LIBRAS”, desses cursos possibilitou a interação de mais de 150 alunos matriculados e que colaboraram efetivamente do projeto entre 2018-2020. A maioria dos estudantes são de baixa renda e residem em Caicó e em cidades circunvizinhas na região do Seridó Potiguar. No período de realização do projeto esses alunos estavam cursando os últimos períodos de sua licenciatura. Por fim, durante todo o projeto os participantes foram auxiliados por monitores bolsistas e voluntários com a colaboração também de profissionais da área de educação de surdos que se prontificaram a auxiliar voluntariamente no projeto.

\section{METODOLOGIA}

Este projeto executou a prática do Tandem no Centro de Ensino Superior do Seridó da Universidade Federal do Rio Grande do Norte. Com isso, tivemos a oportunidade de aprofundar nossos conhecimentos sobre esse processo e auxiliar os futuros professores a conhecer a cultura surda e a língua das comunidades surdas. Deste modo, foi escolhido como natureza do trabalho a pesquisa-ação, segundo as orientações de Tripp (2005). Isso se dá, pois, além de implantar o Tandem, também pudemos avaliar os impactos dessa abordagem na aquisição da Libras e da língua portuguesa por ouvintes e surdos respectivamente. Com isso, todo o trabalho foi desenvolvido seguindo a metodo- 
logia descrita a seguir através de 08 etapas.

\section{Etapa 01 - Firmar parcerias com instituições locais para execução do projeto}

Nesta etapa entramos em contato com membros da Associação de Surdos de Caicó e comunidade surda local para informar sobre a execução e objetivos do projeto. Essa associação vem desempenhando ações para a inclusão social de surdos da região. Houve bastante interesse na participação. Após isso criamos um grupo no Whatsapp para compartilhar informações sobre o projeto, organizar horários e informar os locais de interação.

\section{Etapa 02 - Seleção de monitor}

Um passo importante no projeto foi a seleção do monitor. Além de uma análise curricular foi realizada uma prova com questões objetivas. Assim os alunos escolhidos, a cada ano, já haviam cursado a disciplina Libras. O papel dos monitores foi o de acompanhar e agendar as interações e auxiliar a dirimir alguma eventual dúvida sobre vocabulário que os participantes tiveram de registrar a frequência dos presentes. Os temas das interações foram definidos pelo professor em parceria com o monitor do projeto, nesse caminho foram escolhidos temas atuais que pudessem ser abordados na redação do Enem de cada ano que o projeto está sendo executado.

\section{Etapa 03 - Logística das interações}

Após as etapas anteriores foi iniciado a criação de grupos de interação, sendo em duplas e alguns trios. Tivemos um número maior de ouvintes do que de surdos nos grupos, pois apenas 20 surdos participaram do projeto e mais de 35 ouvintes. Alguns surdos voluntariamente participaram de mais de um grupo. Em alguns momentos os grupos tiveram uma variação de tamanho devido à falta de algum dos interagentes.

\section{Etapa 04 - Definição dos conteúdos linguísticos das interações em tan- dem}

Com base nas competências do marco comum europeu (PORTUGAL, 2019) foi possível estabelecer um roteiro de conteúdos que seriam abordados nas conversas entre os interagentes. 
Além de assuntos que poderiam ser tema da redação do Enem, foi definido os aspectos linguísticos que seriam alvo das discussões entre os interagentes. Contudo todos esses conteúdos foram aprendidos de maneira funcional a medida que a necessidade de serem abordados surgisse a cada encontro (GERALDI, 2011). A fonte dos textos utilizados como mote para as interações foram vídeos da TV INES e notícias de jornais online. Esses vídeos e notícias foram enviados aos interagentes com atencedência de alguns dias, isso permitiu que eles se familiarizassem com algum vocabulário específico que poderia ser usado nas conversas.

\section{Etapa 05 - Elaboração de cronograma e início das interações em tandem}

O monitor do projeto definiu um cronograma de interações, conforme a disponibilidade de cada um, com datas e horários que foram compartilhados no grupo de Whatsapp criado para facilitar a comunicação entre os participantes do projeto. Após isso iniciamos as interações entre os participantes. Esses momentos foram organizados para durar cerca de uma hora e meia. Esse tempo foi dividido em 45 minutos para interação em Libras, onde o surdo auxiliou o ouvinte no uso da língua de sinais, e mais 45 minutos em interação em língua portuguesa na modalidade escrita. Nesse último caso o ouvinte auxiliou o surdo a aprimorar a sua escrita. A interação na modalidade escrita da língua portuguesa ocorreu por meio do Whatsapp e utilizando papel e caneta. A função dos alunos da licenciatura foi muito importante nesse momento, pois eles puderam orientar os surdos nos usos adequados de pronomes, artigos, da concordância verbal, gêneros dos substantivos e outros assuntos. Contudo apenas um aspecto linguístico foi abordado por interação. Isso foi necessário para não desestimular o surdo e para que ele tivesse um maior aproveitamento da interação, pois assim ele pôde se concentrar em um aspecto linguístico de cada vez. Vale salientar que o foco não é puramente o aspecto gramatical, mas sim os processos comunicativos da língua em funcionamento (GERALDI, 2011).

Ao final de cada interação o monitor orientou os ouvintes a produzir um vídeo em Libras no qual ele expusesse o que aprendeu. Esse vídeo foi filmado pelo celular e postado no grupo do Whatsapp dos participantes do projeto. Nesse vídeo os interagentes puderam se autoavaliar e avaliar os colegas. Além disso foi possível também dar sugestões para a melhoria das interações e anotar o que ele aprendeu em cada encontro. Os surdos também tiveram que produzir uma atividade, foi solicitado que eles escrevessem um texto sintetizando o assunto dos diálogos. 


\section{Etapa 06 - Produção audiovisual}

Como forma de ampliar as oportunidades de contato criativo com a Libras, os alunos foram convidados a desenvolver materiais audiovisuais em Libras. Com essa produção os estudantes puderam se engajar na criação de materiais didáticos em língua de sinais e no envolvimento nos processos de editoração de vídeos como objetos educacionais. Esse trabalho pôde contribuir para que os licenciandos pudessem utilizar os conhecimentos adquiridos durante a disciplina e interações no tandem, também, para a produção de materiais didáticos sobre diversos assuntos (VIEIRA-ABRAHÃO, 2012). Além disso, os estudantes puderam estar conscientes da necessidade de adaptar o seu material didático ao público surdo dando ênfase a informações multimodais. Links das playlists com alguns vídeos: encurtador.com.br/jqBIT, encurtador.com.br/dJW05

\section{Etapa 07 - Questionário final de avaliação}

Após todas as interações, utilizamos os vídeos produzidos pelos alunos e os textos produzidos pelos surdos como forma de avaliar o seu desenvolvimento na Libras e na língua portuguesa. Essa avaliação permitiu repensar os caminhos tomados e se seria necessária alguma intervenção para potencializar a aprendizagem.

\section{Etapa 08 - Produção de Guia para a implantação do Tandem Libras/ Português}

Através da análise da experiência adquirida com este projeto de ensino, adquirida pelas observações, produzimos um guia de orientação para a implantação do Tandem Libras/Português em cursos de licenciatura (AUTOR et.al, 2020). O guia foi cadastrado como produto de extensão no sistema de gestão acadêmica da UFRN. Ele aborda aspectos técnicos para a implantação do Tandem, em qualquer nível educacional, e dá uma noção conceitual das teorias envolvidas nessa modalidade de aprendizagem colaborativa. O guia foi escrito usando uma linguagem clara para, com foco em conteúdos práticos. Com ele o leitor poderá conhecer os meios para utilizar o tandem em suas aulas em qualquer nível educacional.

\section{Conteúdos curriculares abordados na prática do Tandem Libras/Portu- guês}

Os conteúdos curriculares abordados nas interações entre surdos e ouvintes foram pensados 
para serem momentos nos quais os participantes pudessem aprimorar as suas habilidades linguísticas. Com isso em mente nos debruçamos sobre o Quadro Comum Europeu de Referência para as Línguas: Aprendizagem, Ensino, Avaliação. Isso foi necessário, pois o Brasil não tem um documento que pudesse servir de referência para a aprendizagem de línguas adicionais. Desse modo, o nosso foco foi proporcionar aos interagentes o nível B1.

Para atingir esse nível segundo o Quadro Comum Europeu de Referência para as Línguas o usuário de ser "capaz de compreender as questões principais, quando é usado uma linguagem clara e estandardizada e os assuntos lhe são familiares (temas abordados no trabalho, na escola e nos momentos de lazer, etc.). É capaz de lidar com a maioria das situações encontradas na região onde se fala a língua-alvo. É capaz de produzir um discurso simples e coerente sobre assuntos que lhe são familiares ou de interesse pessoal. Pode descrever experiências e eventos, sonhos, esperanças e ambições, bem como expor brevemente razões e justificações para uma opinião ou um projeto" (PORTUGAL, 2001).

Isso possibilitou a organização temática das interações de modo que contribuísse para que os interagentes conseguissem atingir o nível B1. Outro fator decisivo na definição dos conteúdos curriculares foi o foco na comunicação com pouca ênfase na metalinguagem. Essa perspectiva funcional da língua adicional deve ser ensinada de uma maneira que o aluno possa participar do mundo social e exercer a sua cidadania.

Em síntese podemos afirmar que as atividades estão divididas em: uso, que compreende a leitura, a escrita e a produção de textos em Libras e língua Portuguesa. As ementas das referidas disciplinas contemplam o "estudo crítico e reflexivo sobre a realidade da comunidade surda brasileira em seus aspectos sociais, econômicos, culturais e legais que orientam e normatizam as políticas de atendimento educacional em instituições de ensino regular e especializado. Estudo das filosofias que embasam a Língua Brasileira de Sinais.

A partir disso, como forma de contemplar os conhecimentos teóricos estudados em sala de aula, o projeto Tandem Libras/ português: aprendizagem colaborativa de línguas proporciona uma imersão na cultura e língua das pessoas surdas. Além disso, ao conhecer as vivências dessas pessoas, os licenciados poderão fazer uma interligação de conceitos cotidianos aos científicos, para que se dê um passo para a reflexão sobre a língua e necessidades das pessoas surdas. Associado a essas perspectivas as interações permearam os seguintes conteúdos curriculares que apresentarei a seguir no Quadro 01. 
Quadro 01 - Relação do Quadro comum europeu com os conteúdos abordados no Tandem

\begin{tabular}{|c|c|}
\hline $\begin{array}{l}\text { Competências do Quadro comum Europeu } \\
\text { para o nível B1 }\end{array}$ & Conteúdos relacionados \\
\hline $\begin{array}{l}\text { Capacidade de compreender as questões } \\
\text { principais, quando são usados uma } \\
\text { linguagem clara e estandardizada e os } \\
\text { assuntos the são familiares }\end{array}$ & $\begin{array}{l}\text { Saúde: diálogo sobre cuidados com o corpo, vacinação, } \\
\text { sedentarismo e alimentação. } \\
\text { Esportes: práticas de esporte, tipos de esportes e esportes } \\
\text { praticados pelos interagentes. } \\
\text { Alimentação saudável: Agrotóxicos, alimentação orgânica, } \\
\text { fast food. }\end{array}$ \\
\hline $\begin{array}{l}\text { Capacidade de lidar com a maioria das } \\
\text { situações encontradas na região onde se fala } \\
\text { a língua-alvo. }\end{array}$ & $\begin{array}{l}\text { Política: Esquerda, direita e problemas sociais do Brasil. } \\
\text { Relações familiares: graus de parentesco, filhos, planejamento } \\
\text { familiar e velhice. }\end{array}$ \\
\hline $\begin{array}{l}\text { Capacidade de produzir um discurso simples } \\
\text { e coerente sobre assuntos que the são } \\
\text { familiares ou de interesse pessoal }\end{array}$ & $\begin{array}{l}\text { Trabalho: profissões, emprego, salário, férias e direitos dos } \\
\text { trabalhadores. }\end{array}$ \\
\hline $\begin{array}{l}\text { Capacidade de descrever experiências e } \\
\text { eventos, sonhos, esperanças e ambições, bem } \\
\text { como expor brevemente razões e } \\
\text { justificações para uma opinião ou um projeto. }\end{array}$ & $\begin{array}{l}\text { Educação: níveis de escolaridade, profissões e planos } \\
\text { educacionais para o futuro. } \\
\text { Preconceito: discriminação de raça, cor, gênero, sexualidade e } \\
\text { condição física. } \\
\text { Lazer: passeios, locais que se deseja visitar e formas de lazer } \\
\text { que os interagentes usufruem. }\end{array}$ \\
\hline
\end{tabular}

Fonte: Autor da Pesquisa

Esses assuntos contribuíram para que os participantes pudessem atingir o nível B1 do Quadro Comum Europeu de Referência para as Línguas. Outros temas transversais surgiram nos momentos de interação, entretanto não foi possível catalogá-los pois as conversas entre os interagentes não se limitaram ao tempo da interação. Foi percebido que antes e depois das interações institucionalizadas os surdos e ouvintes continuaram se comunicando sobre diversos assuntos diferentes, o que potencializou os resultados do projeto. Desse modo, os conteúdos curriculares não se limitaram aos expostos acima, porém as atividades foram focadas nesses assuntos.

\section{RESULTADOS ALCANÇADOS}

Na cidade de Caicó a educação de surdos carece de atenção, pois não existem políticas locais 
que favoreçam esse processo. $\mathrm{O}$ abandono escolar é frequente na comunidade surda local e outros são constantemente reprovados. Isso faz que muitos surdos sejam adultos, mas ainda não tenham concluído o ensino médio. Em resultado disso, vários deles não conseguiram resultados satisfatórios no ENEM tendo que adiar o seu sonho de ingressar em um curso superior. Entretanto, dois surdos que participaram do projeto em 2019 conseguiram aprovação através do Enem nos cursos de Licenciatura em Física e bacharelado em moda do IFRN de Caicó. Atualmente na cidade de Caicó está em funcionamento a Associação Caicoense de Surdos - ACAS e cerca de 40 surdos participam efetivamente das atividades dessa associação, e a aprovação dos dois surdos motivou os seus colegas a também buscar o projeto para se desenvolver.

No que concerne ao desenvolvimento acadêmico dos alunos ouvintes, percebi que vários deles se interessaram pela área da surdez e se integraram em outros projetos e se engajaram na militância em favor da educação de surdos (QUADRO 02), além disso iniciaram a produção de trabalhos de conclusão de cursos nessa área e a participação em outros projetos na área da educação de surdos. A produção dos vídeos, possibilitou a oportunidade de se tornarem multiplicadores do conhecimento adquirido durante a disciplina Libras no curso de Licenciatura do Ceres campus Caicó.

Quadro 02 - Registro da participação de alunos no movimento do dia do surdo.

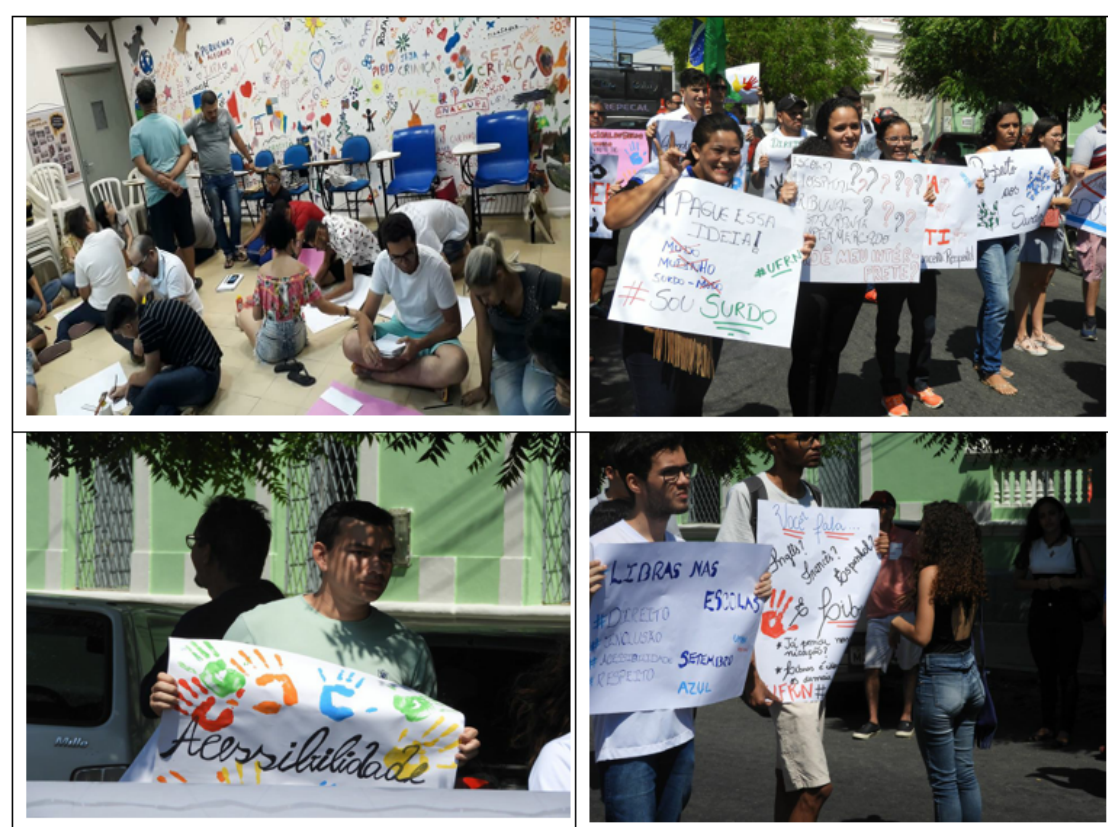

Fonte: Autor do projeto.

Os efeitos deste projeto nos surdos foram evidentes. Os sorrisos nos seus rostos eram revela- 
dos a cada conversa, a cada erro de sinalização dos ouvintes. Um dos resultados mais notáveis foi a aproximação entre dois irmãos, um ouvinte aluno do curso de licenciatura em história e um surdo participante do projeto. Os dois são filhos do mesmo pai, porém com mães diferentes. Eles nunca tinham tido uma conversa até a participação no nosso projeto. Os laços entre eles puderam pela primeira vez ser fortalecidos por meio do diálogo.

Outro resultado relevante foi a aprovação de dois surdos em cursos de graduação, em agora em 2021 um deles foi aprovado em duas universidades diferentes, UFRN e UFERSA. Em adição a isso, foram formadas novas amizades. Esse fato supera qualquer benefício acadêmico obtido com este projeto, pois as relações entre esses dois grupos foram humanizadas e os surdos puderam sair da invisibilidade, pois os laços fraternais estavam feitos. Nesse ímpeto, alguns surdos afirmaram que desejavam que o projeto fosse realizado todos os dias, outros têm mostrado interesse em ampliar a abrangência deste projeto para ações à distância. Porém, para uma maior abrangência necessitamos de mais recursos financeiros e humanos, e no momento não contamos isso.

Como docente pude perceber que ações como essas, mesmo que pequenas, podem contribuir para que vidas sejam mudadas, pois um novo amigo muda nossas vidas. Esse engajamento foi evidente com uma participação ativa de turmas das licenciaturas em Pedagogia, Matemática, História e Geografia (QUADRO 03) Consegui me aproximar mais dos alunos e da comunidade surda de Caicó. Atualmente esses mesmos surdos estão participando de outras atividades dentro da universidade, e isso é um forte indício do efeito do projeto Tandem Libras/ português: aprendizagem colaborativa de línguas.

Quadro 03 - Registro da participação de alunos dos cursos de Licenciatura do Ceres.

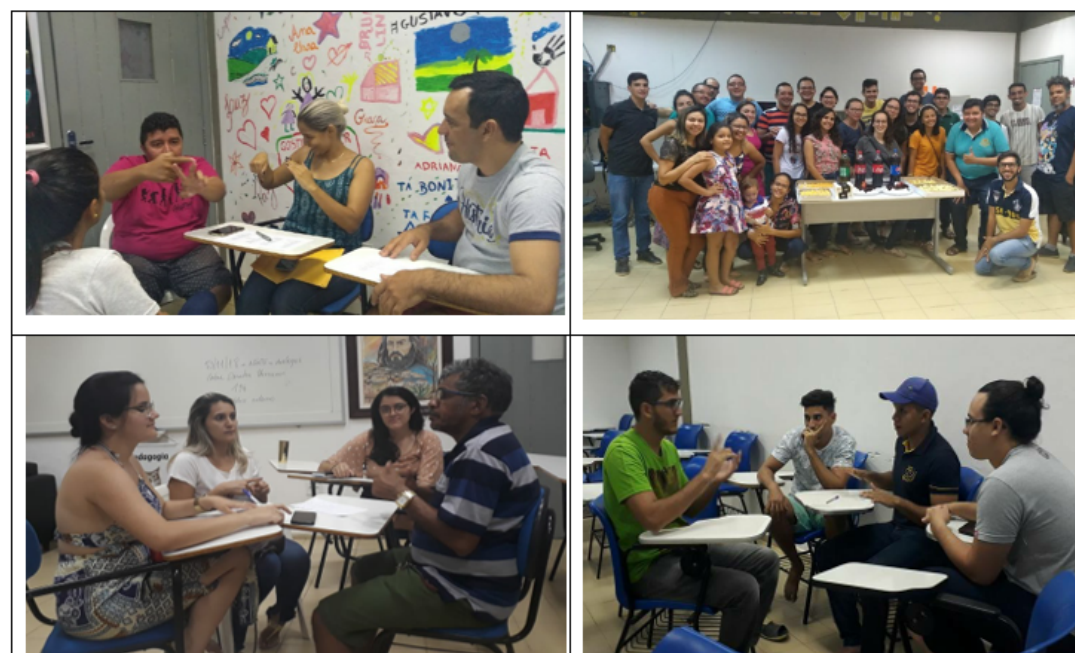

Fonte: Autor do projeto. 
Com a conclusão do projeto os surdos puderam utilizar de maneira aprimorada a modalidade escrita da língua portuguesa e os estudantes dos cursos de Licenciatura do campus Caicó puderam aprimorar suas habilidades no uso da Libras. Como docente, me sinto motivado a continuar com ações como essa para que mais surdos possam ter essa oportunidade. No futuro pretendemos realizar essas interações através de uma Ambiente virtual de aprendizagem através da busca por editais de financiamento. Isso ampliará as fronteiras de execução do projeto atingindo um maior número de participantes. A experiência adquirida na Universidade Federal do Rio Grande do Norte em Caicó foi fundamental para esses planos.

\section{O QUE SE APRENDEU COM A EXPERIÊNCIA}

Existem poucas oportunidades de fazer coisas boas na vida, e quando elas surgem não devemos desperdiçá-las. Essa oportunidade surgiu para mim com a execução deste projeto, pois enxerguei uma oportunidade de resolver dois problemas: a falta de oportunidades de interação em Libras para alunos dos cursos de licenciatura e a necessidade de um maior contato com a modalidade escrita da língua portuguesa pelos surdos. Pude perceber que esses dois grupos que convivem muitas vezes nos mesmos espaços, mas são separados por uma língua, necessitam de uma aproximação. Essa relação conflituosa tem gerado dificuldades principalmente para as comunidades surdas, por serem minoritárias e assim estar mais vulnerável socialmente. Isso pode estar acontecendo, pois, uma parte dos ouvintes desconhece a comunidade surda e suas potencialidades. Assim, é preciso aproximar essas pessoas e humanizar essa relação, pois muitas vezes os surdos são invisíveis em nossa sociedade.

O meu papel como docente da Língua de Sinais Brasileira - Libras (AUTOR, 2019) é criar oportunidades para que meus alunos não possam somente aprender a língua, mas também conhecer uma nova cultura e respeitar os seus membros. Nesse sentido o contato com os surdos possibilitou conhecer o outro, mas não outro que está longe de nós e sim alguém que pode ser de nossa família, nosso vizinho ou nosso amigo. Situações como essas não são facilmente apagadas da memória, pois elas são gravadas como um entalhe em uma pedra.

\section{RELAÇÃO DA PRÁTICA COM OS CONCEITOS DE EXTENSÃO}

Levando em conta que a Extensão Universitária, alicerçada na indissociabilidade entre ensino, pesquisa e extensão, como um processo interdisciplinar, esse trabalho é uma sistematização dessas atividades. A partir da percepção de uma carência na graduação, podemos articular uma ação que 
visou suprir essa carência e estender os conhecimentos pesquisados na UFRN para outros setores da sociedade. Nesse caminho a ACAS teve um papel fundamental em estimular a comunidade surda na participação deste projeto e em um curso de extensão que teve por objetivo auxiliar os surdos no desenvolvimento da escrita de redações com foco na participação do ENEM 2020.

Para além da abrangência regional, este projeto buscou meios de ampliar o seu alcance através do Guia para a implantação do Tandem Libras/Português. Esse material pode contribuir com docentes que queiram implantar a modalidade Tandem em suas instituições. Com isso o nosso projeto permitirá que outras universidades possam também articular o ensino de Libras com ações de extensão por meio do Tandem (AUTOR et.al, 2020).

\section{REFERÊNCIAS}

BENEDETTI, A. M. Dos princípios de tandem ao tandem. In: BENEDETTI, A.M.; CONSOLO, D.A.; VIEIRA-ABRAHÃO, M.H. (Orgs.). Pesquisas em Ensino e Aprendizagem no Tandem Brasil: línguas estrangeiras para todos. Campinas: Pontes Editores, 2010, v. 1, p. 21-46.

CANDIDO, A. Vários Escritos. Rio de Janeiro: Ouro Sobre Azul, 2011.

FERNANDES, Sueli; MOREIRA, Laura Ceretta. Políticas de educação bilíngue para surdos: o contexto brasileiro. Educ. rev., Curitiba, n. spe-2, p. 51-69, 2014 . Disponível em < http://dx.doi. org/10.1590/0104-4060.37014> Acesso em 21 de Julho de 2021.

GERALDI, J.W. O Texto na Sala de Aula. João Wanderley Geraldi ; Milton José de Almeida .. (org) [et.al.]. $1^{\circ}$ Edição São Paulo: Ática, 2011.

AUTOR. LIBRAS: uma reflexão a respeito do histórico de uso do termo. Revista Educação, Artes e Inclusão. Santa Catarina. PPGAV / UDESC, 2019. v. 15, n. 2.

AUTOR. Guia para a implantação do Tandem Libras/Português. São Paulo: Mentes Abertas, 2020, 30 p. Disponível em: https://sigaa.ufrn.br/sigaa/public/departamento/documentos.jsf?lc=pt_ BR\&id=4880 Acesso em: 22 de julho de 2021.

PORTUGAL. Quadro Comum Europeu de Referência para as Línguas: Aprendizagem, Ensino, Avaliação. Cidade de Lisboa: Asa. 2001. Disponível em:< http://area.dge.mec.pt/gramatica/Quadro_Europeu_total.pdf $>$ Acesso em: 15 de junho de 2019

QUADROS, R. M. Ideias para ensinar português para alunos surdos / Ronice Muller Quadros, Magali L. P. Schmiedt. - Brasília : MEC, SEESP, 2006. 120 p. 
SILVA, A. D. P. O ensino de literatura hoje: da crise do conceito à noção de escritas. Campina Grande: EdUEPB, 2016.

SKLIAR, C. A localização política da educação bilíngue para surdos. In: SKLIAR, C. (org.). Atualidade da educação bilíngue vol.2: interfaces entre pedagogia e linguística. Porto Alegre: Mediação, 2017.

STREIECHEN, M. E. Por que o surdo escreve diferente? Revista Interlinguagens. Volume 2. Universidade Estadual Do Centro Oeste - Unicentro. Irati -PR, 2011.

TRIPP, D. Pesquisa-ação: uma introdução metodológica. Educ. Pesqui., Dez 2005, vol.31, no.3, p.443-466.

VIEIRA-ABRAHÃO, M. H. A Formação do Professor de Línguas de uma Perspectiva Sociocultural. Signum. Estudos da Linguagem, v. 15, p. 457-480, 2012

VYGOSTSKY, L.Pensamento e linguagem.Edições Antídoto, Lisboa, 1979. 